\title{
Investigation of the Availability of Occupational Health and Safety Related Documents on the Construction Sites in Windhoek, Namibia
}

\author{
Emma Maano Nghitanwa \\ School of Nursing, University of Namibia, Windhoek, Namibia \\ Email: enghitanwa@unam.na
}

How to cite this paper: Nghitanwa, E.M. (2018) Investigation of the Availability of Occupational Health and Safety Related Documents on the Construction Sites in Windhoek, Namibia. Open Journal of Safety Science and Technology, 8, 1-12. https://doi.org/10.4236/ojsst.2018.81001

Received: June 20, 2017

Accepted: March 6, 2018

Published: March 9, 2018

Copyright $\odot 2018$ by author and Scientific Research Publishing Inc. This work is licensed under the Creative Commons Attribution International License (CC BY 4.0).

http://creativecommons.org/licenses/by/4.0/

\begin{abstract}
Background: Construction industry is regarded as dangerous industry with more occupational injuries and accidents. Documents related to Occupational Health and Safety (OHS) should be utilised and kept in the construction sites to show that the construction sites are applying to national and international OHS legislation requirements. Objective: To review the documents to determine the presence of OHS related documents utilized on the construction sites in OHS provision. Methods: A quantitative, descriptive study was conducted among ten construction sites in Windhoek, Namibia to investigate the availability of OHS related documents in the study sites. Data were collected with the document review checklist. Data were analysed using SPSS software program. Results: The study found that many construction sites did not have OHS related documents which show poor compliance towards OHS national and international legislation requirement in OHS provision. Conclusion: The study concluded that absence of OHS related documents on the construction sites is negatively affecting the implementation of OHS on the construction sites It was recommended that employers should ensure that OHS program is developed at workplaces and OHS related documents should be available for utilization in all workplaces according to the legislative requirements.
\end{abstract}

\section{Keywords}

Occupational Health, Occupational Safety, Document, Construction, Industry

\section{Introduction}

The construction industries are indeed significant for any nation's socio economic development, yet the sector encounters frequent and high work-related 
accident rates and subsequent ill health [1]. Over 1000 construction workers die annually throughout the world due to work-related accidents and diseases [2]. Furthermore, construction work is dynamic in nature with working environment changes, poor working conditions, poor working environment and with workers being exposed to several hazards such as noise, dust, vibration and ergonomic conditions [3].

To address the challenges faced by construction industries, Occupational Health and Safety Management system (OHSMs) model was developed by the International Labour Organization (ILO) in 2001 for employers to have a framework for a continuous systematic management and improvement of OHS policies, plans, programmes and projects [4] in order to promote occupational health and safety of workers at workplaces. The steps for OHSMs are policy, organizing, planning and implementation, evaluation and action for improvement [5]. OHSMs states the requirements for workplaces to develop Occupational Health and Safety (OHS) programs by making provision for the availability of certain documents to promote OHS at work places. During the process of OHSMs, OHS policy should be developed in the workplaces which should show that the employer is committed to maintain health and safety of workers. The OHS policy should state the provision on workplace inspections which include the assessment of the environmental factors that may affect workers health such as provision of hygiene or welfare and sanitation facilities, PPE provision and availabilities of hazards in the working environment [5].

According to [6] who conducted a study to assess the effect of OHSMs on work-related accident rate in South Korea's construction industry the accident rates decreased by $67 \%$ and fatality accident rates decreased by $10.5 \%$ in construction companies which implemented OHSMs. However, the study also found out that OHSMs were not implemented in the majority of construction companies. Study conducted in Namibia among Chinese construction companies revealed that the majority of construction workers were not aware of the existence of OHS policy or OHS related documents in their respective construction sites [7]. Therefore, the implementation of an effective occupational health and safety services would result in a decreasing of occupational diseases and injury and reduction of the costs associated with workplace accidents [4].

In Namibia, the Labour Act [8] was promulgated to ensure health, safety and welfare of employees in the workplace. The act (Labour Act No. 11 of 2007) states on the health, welfare and safety of employees at work where it described the expected duties of employer toward employees which include the employers' duty to ensure OHS documents are available on the working environment. Furthermore, the Regulations relating to the Health and Safety of Employees at Work (No. 156 of 1997) which came into force under the Labour Act (Act No. 6 of 1992) as amended by [8] is a framework governing the status of OHS in Namibia as it makes provisions for the responsibilities and duties of employers in the provision of OHS in order to maintain the health and safety of employees at 
work [9]. The Regulations relating to the Health and Safety of Employees at Work (No. 156 of 1997) require employers to conduct medical surveillance which include pre-placement examination, periodic medical examination and exit occupational medical examinations to assess the workers fitness for employment [9]. In addition, it is required for each workplace to have a first aid station and certified first aiders to assist when first aid is needed at work [9]. Further, the requirement for every construction site to have an emergency plan in place with the appointment of emergency coordinator known by all workers on site as well as the list of emergency numbers to be called in case of emergency was stated [9]. Therefore, it is a legal requirement to have a qualified, certified first aider available on site at all time and first aid kit with all necessary supply with the location known by all workers [9]. The construction site should keep accident register, injury on duty reporting forms on site which they are using to report accidents at the regulatory authority [9]. On the other hand, the claim for death benefit should be submitted to the Social Security Commission, for death benefit payment [10].

Furthermore, employers should ensure that inspections are being conducted in the construction sites to identify hazards by means of using a checklist and procedures for action after inspection should be stated [11]. The literatures also argued about the importance of OHS induction to new construction workers and the content of the induction modules and procedures to be used in order to prevent accidents [12] [13]. Furthermore, [1] argued that OHS training is required on recruitment, induction or being exposed to new risk, change in responsibility, new equipment or too young or disabled worker, as the latter categories are prone to injuries. Furthermore, it is imperative that construction workers inducted or trained should sign a register to proof that training and induction has been conducted [11]. Similarly, [14] indicated the duty of a supervisor to ensure that orientation of new staff members is conducted with emphasis on health and safety awareness during work. The induction should include but not limited to the following topics: introduction to job site, OHS rules and regulations, hazard information, PPE requirements, fire protection, emergency preparedness, first aid, injuries reporting, permit requirements and disciplinary procedures [15].

Safety training should be conducted on regular basis to make the workers aware of the risk at workplaces and how their behaviours may affect risks [16]. In this regard, safety training and communication e.g. tool box talk raises hazard awareness, develop knowledge and skills, and reinforce workplaces safety practices [17].

Moreover, psychological stressors should also be assessed at work and employer should ensure that the normal psychosocial wellbeing of workers is promoted at workplaces [18]. Furthermore, Discrimination (Employment and Occupation) Convention 1958 (No 111) states that, the ratified member states should declare a national equality policy to eliminate discrimination at 
workplaces. The convention further states that workers should be free from harassment based on race, colour, religion, political affiliation or social background [19].

Over $70 \%$ of workers are living with HIV provision of treatment, therefore, preventive measures and protecting the right of people living with HIV/AIDS from discrimination and stigma should be adhered to [20]. In addition, ILO code of practice 2001 stated that the member states should develop HIV aid policy at work policy at work in collaboration with workers, employers and government. The researchers could not find any literature regarding the investigation of the availability of OHS related documents in the Namibian construction industry. Therefore, the researchers found it necessary to assess the construction sites for OHS related documents to determine the implementation of OHS. The objective of the study was to determine the presence of occupational health and safety documents required by legal framework in the construction industry of Windhoek in Namibia.

\section{Method}

The study was conducted for a period of six (6) months, from October 2014 to March 2015. A quantitative, descriptive, cross-sectional study design was applied to assess the presence of OHS related documents in the participated construction sites using a document review checklist. This study was conducted in Windhoek, Namibia, among the ten construction sites, in Windhoek municipality in operation during the study. The target population include all 13 construction sites with project running during the study period. The city of Windhoek's municipality was selected because of its increase in population which leads to the increment in construction activities. Windhoek is the capital city of Namibia situated in Khomas region on the central part of Namibia.

The researchers obtained the data base from the city of Windhoek municipality for the approved construction sites operating during the study which was used as sampling frame. There were 15 construction sites operating during the study, two construction sites were used for pilot test to rule out any problems with the questions format and if there could be limitations in the responses. Furthermore, piloting was conducted in order to improve reliability and validity of data collection tools and to incorporate comments from the participants in to the final revised data collection instrument. The researchers ensured that piloting was conducted in the construction sites with similar characteristics to those participating in the main study. The two construction sites used for piloting where excluded from the main study. Census sampling was used to include all available thirteen construction sites. However, out of thirteen construction sites, only ten construction site managers authorized the researcher to conduct document review using checklist.

The data collection tool used was a document review checklist developed by the researchers based on literature review to assess the OHS documents on the 
targeted construction sites. The document review checklist consisted of five sections which include personal health resources related documents, hazard identification and control, occupational health and safety management provision, OHS induction and training and psychosocial work environment related documents. The checklist asked if different listed OHS related documents were available on the construction site and two columns for "yes" and "no" respectively. The researchers tick in the "yes" column if the document is available and "no" if the document in question is not available.

After the data collection process, all the data collection tools were reviewed and coded numerically. Data were entered in the SPSS software program version 23.0 and the database was created and cleaned for missing data before running statistical analysis. Data entry was performed by the researchers in a private office to prevent other people from having access to documents. The researchers used the Statistical Package for Social Science (SPSS) version 23.0 (SPSS Inc. Chicago, Illinois, USA) computer program to perform the analyses. Raw data was initially reviewed for consistency, completeness and the missing values were verified against the source. Study findings are presented in frequencies, percentages and other descriptive measures.

Ethical clearance was sought and obtained from the University of South Africa (UNISA), Department of Health Studies research ethical committee before the execution of the study. Furthermore, permission to conduct the study was sought and obtained from the site managers of 13 construction sites participated in the study before data collection. Confidentiality was maintained during and after the study.

\section{Results}

The findings emanated from document review checklist are described here after.

\subsection{Personal Health Resources Documents in the Construction Sites}

The analysis from the document review indicated that job descriptions were available for each job categories in $5(50.0 \%)$ of the construction sites compared to $5(50.0 \%)$ construction sites without job descriptions of all job categories. Furthermore, the analysis shows that only $2(20.0 \%)$ of the construction sites stated the health and safety responsibilities of construction workers in the job descriptions, thus is contradicting the $8(80.0 \%)$ of the construction sites. Regarding the availability of pre-employment medical questionnaire filled by each workers and availability of employment screening reports the analysis indicates that all $10(100 \%)$ construction sites had no pre-employment medical questionnaire and employment screening reports (Table 1).

\subsection{Documents Regarding Hazard Identification and Control on Study Sites}

Regarding the availability of accident register in the construction sites as depicted 
Table 1. Availability of documents regarding personal health resources in the construction sites $(\mathrm{N}=10)$.

\begin{tabular}{lccc}
\hline \multicolumn{1}{c}{ Element } & Response & Frequency & Percentage \\
& category & (n) & (\%) \\
\hline $\begin{array}{l}\text { 1) Are job descriptions available for each workers job } \\
\text { categories? }\end{array}$ & Yes & 5 & $50.0 \%$ \\
$\begin{array}{l}\text { 2) Are health and safety responsibilities stated in the workers } \\
\text { job descriptions? }\end{array}$ & Yes & 2 & $50.0 \%$ \\
$\begin{array}{l}\text { 3) Are health and safety committee meeting minutes } \\
\text { available? }\end{array}$ & No & 8 & $80.0 \%$ \\
$\begin{array}{l}\text { 4) Does the company keep pre-employment medical } \\
\text { questionnaire filled by each worker? }\end{array}$ & No & 7 & $30.0 \%$ \\
& Yes & 0 & $0 \%$ \\
5) Are pre-employment screening reports available? & No & 10 & $100 \%$ \\
& Yes & 0 & $0 \%$ \\
6) Are the list of names and positions of workers with & Yes & 10 & $100 \%$ \\
specific health and safety responsibilities available? & No & 6 & $40.0 \%$ \\
\hline
\end{tabular}

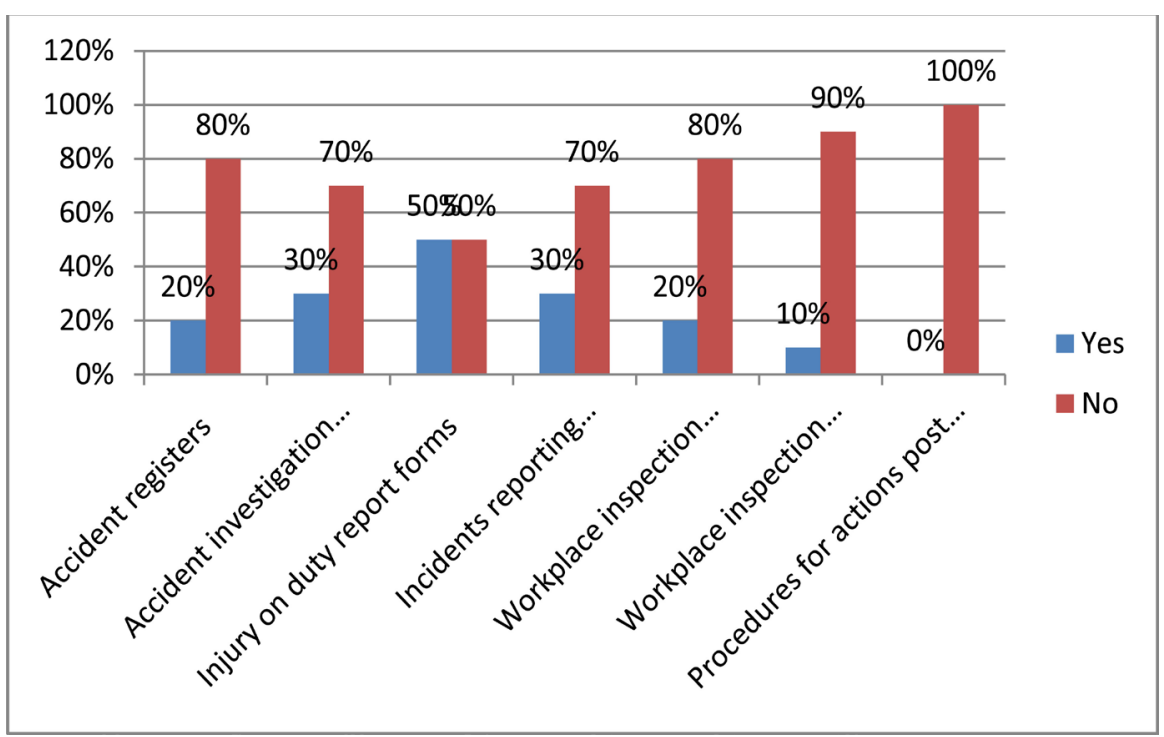

Figure 1. Availability of documents regarding hazard identification and control $(\mathrm{N}=10)$.

in Figure 1, the analysis shows that $2(20 \%)$ of the construction sites were found to have accident registers while $8(80 \%)$ had no accident registers available. Furthermore, the analysis indicated that accident investigation procedures were found in 3 (30\%) of the construction sites opposing 7 (70\%) sites without accident investigation procedures. Surprisingly, the analysis further shows that workplace inspection was found to be carried out in only 2 (20\%) construction sites while $8(80 \%)$ does not conduct workplace inspections. However, written procedures for action to be taken after workplace inspection were not found on any study sites. 


\subsection{Documents Pertaining to the Provision of Occupational Health and Safety Management System in Construction Sites}

The analysis indicated that only 4 (40.0\%) of the construction sites had OHS policy contradicting 6 (60.0\%) without OHS policies. Regarding the availability of Regulation No. 156 of 1997, Regulations related to the health and safety of employees at work, the analysis illustrated that all $10(100 \%)$ construction sites had no copies of the mentioned regulations.

Additionally, the analysis indicated that $6(60.0 \%)$ of the construction sites inspected had health and safety plan for the project contradicting $4(40.0 \%)$ of the construction sites found without OHS plan. However, the analysis shows that only 3 (30.0\%) of the construction site's OHS plan clearly stated the scope of work opposing 7 (70.0\%) of the construction sites. The analysis further shows that safe working procedures were only available on 3 (30.0\%) of the construction sites while the majority of 7 (70.0\%) of the construction sites did not have safe working procedures. The analysis also indicated that company safe work procedures relevant to the construction project were found on $2(20.0 \%)$ of the construction sites in contrary with $8(80.0 \%)$ construction sites without safe working procedures relevant to the project. Surprisingly, the analysis shows that all $10(100 \%)$ construction sites had no medical surveillance reports neither sickness absence monitoring procedures available. Similarly, the analysis revealed that all $10(100 \%)$ construction sites had no smoking policy. The summary of the findings regarding OHS provisions.

\subsection{Documents Related to Occupational Health and Safety Induction and Training in Construction Sites}

Regarding the documents regarding OHS induction and training the analysis shows that $8(80.0 \%)$ of the construction sites had no induction procedures and induction modules for new workers and only $2(20.0 \%)$ of construction sites had induction modules. However, the analysis indicated that only 1 (10.0\%) construction site keeps signed register of workers completing the induction program while $9(90.0 \%)$ construction sites had no register for workers completed induction programs.

Furthermore, the analysis revealed that, 9 (90.0\%) of the construction sites had no registers for periodic safety and health training available and only 1 (10.0\%) construction site were found to have OHS training register signed by trained workers.

\subsection{Availability of Policies Regarding Psychosocial Work Environment}

As shown in Figure 2, the analysis regarding policies pertaining to psychosocial work environment, shows that $9(90.0 \%)$ of the construction sites had no stress management policy, neither policy for rewarding workers on health and safety promotion contradicting $1(10.0 \%)$ construction site respectively. The analysis 


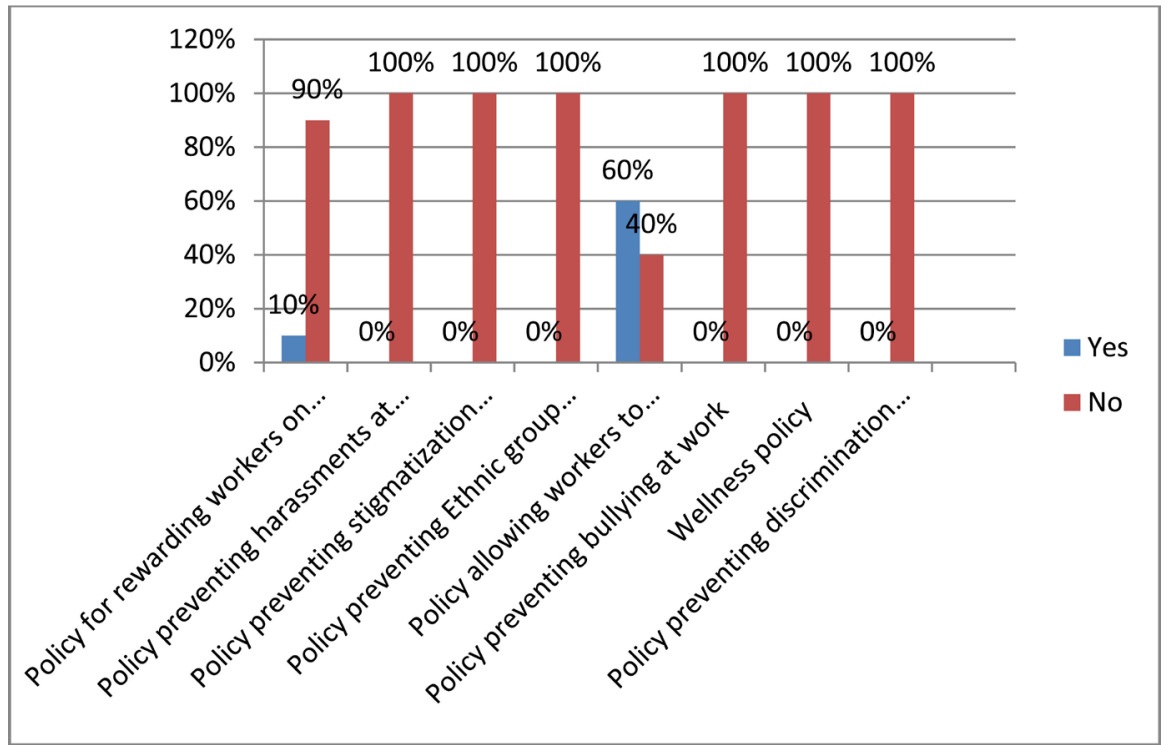

Figure 2. Availability of policies regarding psychosocial work environment.

furthermore, shows that all $10(100 \%)$ construction sites had no policy preventing harassments at work, policy preventing stigmatization on HIV infected workers, policy preventing bullying at work, policy preventing discrimination based on religious diversity neither policy preventing ethnic group discrimination. Regarding the availability of wellness policy the analysis shows that it was not available in all $10(100 \%)$ construction sites.

\section{Discussion}

The study findings imply that the provision of OHS related document is a challenge evidenced by non availability of these documents in several study sites. The current study findings showed that job descriptions which state the OHS responsibility of each worker were only available at one-fifth of the study sites. This contradicts the findings from Ngamthampunpol's [15] assessment of safety management in the Thai construction industry, which indicated that the OHS responsibilities of all employees were clearly defined in all job descriptions. The findings of this study showed that accident registers were found at only one-fifth of the study sites. The findings are against the statutory requirement of the regulation 22 (1) (a) \& 6 (1) and 25 (1) (1) (b) of the Regulations relating to health and safety of employees at work (No 156 of 1997) that state that it is the responsibility of the employer to notify the chief inspector about accidents that would have occurred at the workplaces and to keep the register of accident occurrence for a period of five years. The accident register should be used to record all accidents occur in the construction sites. Furthermore, the current study findings indicated that three-tenths of the considered construction sites had incident reporting procedures. The findings are largely against the International Labour Organization-Occupational Safety and Health an (ILO-OSH) [5] guideline which states that all organisations should maintain the documents regarding 
occupational health and safety management system such as documents regarding work-related injuries. The results are implying the poor recording and poor reporting system. It was also noted from the findings of the current study that, checklists for workplace inspection were only available at few study sites. The findings are against the report by [11] which states the importance of using a checklist for inspection in order to standardise the worksite inspection and to ensure that the inspection is completely conducted. Moreover, the findings from the current study indicated further that written procedures on the action that must be taken after workplace inspection were not found at any of the study sites. According to the report by [11], any hazard or risk identified during the site inspections should be addressed immediately following that organisation's written safe working procedure.

The current study findings showed that only two-fifths of the study sites had a health and safety policy. This concurs with the findings from a study by [21] conducted in Ghana where they identified that there was a challenge regarding the adoption of an OHS national policy. However, study by [22] on European Union OHS legislations show that 95\% of participants indicated that they had access to OHS Act. The findings also surprisingly showed that all study sites had no medical surveillance reports. The findings are not in line with the requirement of the section 219 of the Regulations relating to health and safety of employees at work, which calls for the employer to arrange for pre-employment screening, periodic medical examination and exit medical examination free of charge to the workers [9]. The current study findings indicated that job risk assessment policies were found at a few study sites only. The findings are against the requirement of the National occupational health policy of Namibia [23] which indicates that it is the responsibility of the employer to develop a policy addressing the identification of hazards by means of risk assessments.

The current study findings indicated that the majority of study sites had no induction procedures. The findings are similar with those from a study conducted by [7] on the Namibian construction industry, where by the majority of participants indicated that they were not given formal induction but were instructed to learn from the older workers tasked with showing them the industry's ropes. Contrary to this, however, is the study by [22] which, in its evaluation of the European Union (EU) legislation on risk assessment and OHS preventive measures, found out that the $89 \%$ of the participants confirmed that they had been trained and oriented on safety at work. Lastly, the current study findings revealed that the significant majority of study sites did not have policies seeking to promote the psychosocial wellbeing of workers. The findings contravene section 5 (2) of the Labour Act of Namibia (Act No 11 of 2007) which prohibits any form of discrimination against any individual at work [8].

\section{Conclusion and Recommendations}

The study findings conclude that the OHS practice is poor in the study sites evi- 
denced by the lack of most documents regarding OHS which implies that OHSMs are not implemented in most study sites. However, the study was only conducted in the construction sites in Windhoek and results could not be generalised. There is a need to improve OHS in the construction industry by implementing OHS management system and ensure the documents required for OHS are available and utilised on the construction sites. The researchers recommended that employers should ensure that the organization is performing its work based on the statutory legislative requirements of the regulations governing OHS in Namibia. Furthermore, employers should ensure that all OHS legislations should be displayed in an accessible place at workplaces for workers to acquaint themselves with OHS requirements which could improve their awareness towards OHS. In addition, employers should ensure that OHS officers, OHS representatives, OHS committees are appointed at workplaces to monitor OHS in the workplaces and to monitor the working environment, thus reduction in occupational accidents, injuries and diseases. Another recommendation is for the employers together with OHS representatives to ensure that OHS program is developed at every workplace by developing and implementing the written OHS policy which should state the management commitment towards OHS at work. Based on the research findings, the practical guidelines were developed to improve the OHS for workers in the Windhoek construction industry.

\section{Acknowledgements}

The researchers would like to thank the site managers for the studied construction sites for giving permission to conduct the study.

\section{Declarations}

The researchers declare no conflict of interest and no funding was received for the study.

\section{References}

[1] Phoya, S. (2012) The Practice of Risk Assessment, Communication and Control Health and Safety Risk Management in Building Construction Sites. Degree Thesis, Chalmers University of Technology, Gothenburg.

[2] Hinze, J. and Giang, G. (2008) Factors Associated with Construction Worker Eye Injuries. Safety Science, 46, 634-645.

http://www.sciencedirect.com/science/article/pii/S092575350700104X?via\%3Dihub https://doi.org/10.1016/j.ssci.2007.06.015

[3] Pinto, A., Nunes, I.L. and Ribeiro, R.A. (2011) Occupational Risk Assessment in Construction Industry-Overview and Reflection. Safety Science, 49, 616-624. http://www.sciencedirect.com/science/article/pii/S0925753511000051 https://doi.org/10.1016/j.ssci.2011.01.003

[4] Taderera, H. (2012) Occupational Health and Safety Management Systems: Institutional and Regulatory Frameworks in Zimbabwe. International Journal of Human Resource Studies, 4, 99-117. https://doi.org/10.5296/ijhrs.v2i4.2149

[5] International Labour Organization (2001) Guidelines on Occupational Safety and 
Health Management Systems. ILO Publications, Geneva.

[6] Yoon, S.J., Lin, H.K., Chen, G., Yi, S., Choi, J. and Rui, Z. (2013) Effect of Occupational Health and Safety Management System on Work-Related Accident Rate and Differences of Occupational Health and Safety Management System Awareness between Managers in South Korea's Construction Industry. Safety and Health at Work, 4, 201-209. https://www.ncbi.nlm.nih.gov/pmc/articles/PMC3889079/ https://doi.org/10.1016/j.shaw.2013.10.002

[7] Herbert, J. and Iipumbu, S. (2009) Chinese Investments in Namibia, a Labour Perspective. Labour Resource and Research Institute, Windhoek. http://namibia.leadr.msu.edu/items/show/56

[8] Republic of Namibia (2007) Labour Act, No 11, 2007. Government Printers, Windhoek.

[9] Republic of Namibia (1997) Regulations Relating to the Health and Safety of Employees at Work. Regulation R.156, in Terms of the Labour Act, 1992 (Act No 6, 1992, as Amended). Government Printers, Windhoek.

[10] Republic of Namibia (1994) Social Security Act (Act No. 34 of 1994). Government Printers, Windhoek.

[11] WorkSafeBc (2013) How to Implement a Formal Occupational Health and Safety Program.

http://www.worksafebc.Com/publications/healthandsafety/bytopic/assets/pdf/howt o implement_ohs.Pdf

[12] Zhao, Z., Zhao, X., Davidson, K. and Zuo, J. (2012) A Corporate Social Responsibility Indicator System for Construction Enterprises. Journal of Cleaner Production, 29-30, 277-289.

http://www.sciencedirect.com/science/article/pii/S0959652611005774 https://doi.org/10.1016/j.jclepro.2011.12.036

[13] Geminiani, F.L. (2008) A Model to Improve the Effectiveness of the Occupational Health and Safety Inspectorate Function Relative to South African Construction. Doctoral Thesis, Nelson Mandela Metropolitan University, Port Elizabeth.

[14] Bahn, S. and Barratt-Pugh, L. (2012) Evaluation of the Mandatory Construction Induction Training Program in Western Australia: Unanticipated Consequences. Evaluation and Program Planning, 35, 337-343.

https://www.ncbi.nlm.nih.gov/pubmed/22410166 https://doi.org/10.1016/j.evalprogplan.2011.11.006

[15] Ngamthampunpol, D. (2008) An Assessment of Safety Management in the Thai Construction Industry. Doctoral Dissertation, George Washington University, Washington DC.

[16] Chi, S. and Han, S. (2013) Analyses of Systems Theory for Construction Accident Prevention with Specific Reference to OSHA Accident Reports. International Journal of Project Management, 31, 1027-1041.

http://www.sciencedirect.com/science/article/pii/S0263786312001809 https://doi.org/10.1016/j.ijproman.2012.12.004

[17] Olson, R., Varga, A., Cannon, A., Jones, J., Gilbert-Jones, I. and Zoller, E. (2016) Toolbox Talks to Prevent Construction Fatalities: Empirical Development and Evaluation. Safety Science, 86, 122-131.

http://www.sciencedirect.com/science/article/pii/S0925753516000461 https://doi.org/10.1016/j.ssci.2016.02.009

[18] Burton, J. (2010) WHO Healthy Workplace Framework and Model: Background and Supporting Literature and Practice. WHO, Geneva. 
[19] International Labour Organization (1958) Discrimination (Employment and Occupation) Convention No 111 of 1958. International Labour Organization, Geneva.

[20] International Labour Organization (2006) Promotional Framework for Occupational Safety and Health Convention No 187 of 2006. International Labour Organization, Geneva. ILO Publications.

http://www.ilo.org/dyn/normlex/en/f?p=NORMLEXPUB:12100:0::NO::P12100_ILO_ CODE:C187

[21] Annan, J., Addai, E.K. and Tulashie, S.K. (2015) Short Communication a Call for Action to Improve Occupational Health and Safety in Ghana and a Critical Look at the Existing Legal Requirement and Legislation. Safety and Health at Work, 6, 146-150. http://www.sciencedirect.com/science/article/pii/S2093791115000025 https://doi.org/10.1016/j.shaw.2014.12.002

[22] Niskanen, T., Naumanen, P. and Hirvonen, M.L. (2012) An Evaluation of EU Legislation Concerning Risk Assessment and Preventive Measures in Occupational Safety and Health. Applied Ergonomics, 43, 829-842.

https://www.ncbi.nlm.nih.gov/pubmed/22233692

https://doi.org/10.1016/j.apergo.2011.12.003

[23] Ministry of Health and Social Services of Namibia (2006) National Occupational Health Policy. Ministry of Health and Social Services, Windhoek. 